\section{Saving the brain}

\section{By Lev Osherovich, Senior Writer}

In 2010, the American Academy of Pediatrics advised against postnatal use of high-dose dexamethasone, a powerful glucocorticoid used to boost circulation and lung function in preterm infants, because of the risk of stunted brain development. ${ }^{1}$ Now, researchers at the University of California, San Francisco have found that although the fallback glucocorticoid hydrocortisone poses a similar risk, ${ }^{2}$ there may be a way to blunt the negative effects of glucocorticoids on the brain by using smoothened. ${ }^{3}$ Safety concerns of such an approach will have to be addressed next.

Premature delivery is associated with cerebral palsy and developmental delay caused by hypoxia or intraventricular hemorrhage. Glucocorticoids are used to counter hypotension and breathing problems in about $20 \%$ of cases of premature delivery, said Emily Tam, assistant professor of neurology and pediatrics at UCSF. "These are major problems for which there aren't other good options."

Tam led a team that used MRI to monitor brain development in 172 premature infants, including 36 who received either hydrocortisone or dexamethasone. Compared with untreated premature infants, steroidtreated patients had an average decrease of $10 \%$ in the volume of the cerebellum, a part of the brain involved in motor function and speech.

Results were published in Science Translational Medicine.

Tam said previous clinical studies hinted at adverse effects of high-dose dexamethasone on brain development and led to a search for safer glucocorticoids for infants. The finding that the next best option-hydrocortisone-also stunts cerebellum development puts clinicians in a tough spot, she said.

Children with smaller cerebellums have cognitive and motor problems, but without the aid of any kind of glucocorticoid there is a risk of even more severe brain injury due to hypoxia, Tam told SciBX.

She plans to follow up with a long-term study of brain development and cognitive function in patients who received glucocorticoid therapy as newborns.

\section{Smoothening wrinkles}

Meanwhile, a separate UCSF group led by David Rowitch has come up with a potential solution to glucocorticoid-induced brain damage in premature infants.

The strategy involves activating smoothened (SMO), a key regulator of the hedgehog transcriptional pathway, to induce the brain-specific expression of a glucocorticoid-degrading enzyme called hydroxysteroid 11- $\beta$ dehydrogenase 2 (HSD11B2; HSD2).

In 2009, Rowitch and colleagues found genetic evidence that activating SMO decreased the severity of brain damage caused by glucocorticoids. ${ }^{4}$ In both cell culture and in mice, glucocorticoids prevented the growth of cerebellar neurons. This effect was abrogated by activating mutations in SMO. Rowitch is a Howard Hughes Medical Institute investigator and professor of pediatrics and neurosurgery at UCSF.

In the new study, Rowitch teamed up with James Chen, associate professor of chemical and systems biology and chemistry at Stanford University School of Medicine, to recreate the genetic effects of SMO activation using small molecule SMO agonists. The hope, said Rowitch, was to counteract the growth-retarding effects of glucocorticoids in the cerebellum without interfering with the beneficial effects of glucocorticoids in other tissues.

The team found that cultured neurons treated with a small molecule SMO agonist had higher levels of HSD2 than vehicle-treated controls.

Indeed, the SMO agonist blocked the inhibitory effects of dexamethasone and prednisolone on cultured neuron proliferation compared with vehicle control.

Cerebellums of mice receiving a systemically delivered SMO agonist plus prednisone had higher levels of neuronal survival and proliferation than controls receiving prednisone alone.

The results of Rowitch's studies were published in Science Translational Medicine.

\section{Window of opportunity}

Rowitch thinks SMO agonists could be used as an adjunct to glucocorticoid therapy in premature infants.

He noted that in his mouse studies, a brief pulse of SMO agonist during the first week of life triggered a protective effect in the brain but did not interfere with the beneficial effects of glucocorticoid signaling on lung development.

However, rodent studies and human case studies have shown that activating mutations in SMO can lead to medulloblastoma, a common pediatric brain cancer.

Rowitch noted that his team checked the brains of mice transiently treated with the SMO agonist and found no sign of tumors but acknowledged that more preclinical work is needed to rule out concerns about triggering tumor growth.

"Our tox studies are inadequate for going forward into the clinic, so we will need longer and larger-scale studies in at least one other species," said Rowitch.

Rowitch is looking for evidence of involvement of glucocorticoids and the hedgehog pathway in other neurological disorders including Down syndrome and hypoxia-induced cerebral palsy.

He did not file for IP but noted that the SMO agonist used in his study is patented by Pfizer Inc.

\section{Osherovich, L. SciBX 4(44); doi:10.1038/scibx.2011.1225}

Published online Nov. 10, 2011

\section{REFERENCES}

1. Watterberg, K.L. et al. Pediatrics 126, 800-808 (2010)

2. Tam, E.W.Y. et al. Sci. Transl. Med.; published online Oct. 19, 2011; doi:10.1126/scitranslmed.3002884

Contact: Emily W.Y. Tam, University of California, San Francisco, Calif. 


\section{ANALYSIS}

e-mail: emily.tam@ucsf.edu

3. Heine, V.M. et al. Sci. Transl. Med.; published online Oct. 19, 2011; doi:10.1126/scitransImed.3002731

Contact: David H. Rowitch, University of California, San Francisco, Calif.

e-mail: rowitchd@peds.ucsf.edu

4. Heine, V.M. \& Rowitch, D.H. J. Clin. Invest. 119, 267-277 (2009)

\section{TARGETS \& MECHANISMS}

COMPANIES AND INSTITUTIONS MENTIONED

American Academy of Pediatrics, Elk Grove Village, III.

Howard Hughes Medical Institute, Chevy Chase, Md.

Pfizer Inc. (NYSE:PFE), New York, N.Y.

Stanford University School of Medicine, Stanford, Calif. University of California, San Francisco, Calif. 